\title{
Densidade colimétrica das áreas de extrativismo de ostras em relação aos fatores ambientais em Cananeia (SP)
}

\author{
Colimetric density assays of oyster harvesting areas in \\ relation to environmental factors in Cananeia (SP)
}

Sonia Assami Doi', Edison Barbieri², Hélcio Luis de Almeida Marques ${ }^{3}$

口-

\begin{abstract}
RESUMO
A água nas áreas de extrativismo de ostras do Estuário de Cananeia foi avaliada por meio da análise colimétrica durante o período de 2005 a 2011. Averiguou-se que a média geométrica dos coliformes termotolerantes (18,80 NMP.10O mL'1) está dentro dos limites permitidos pelo CONAMA 357/2005, mas o percentil não alcançou o mínimo estabelecido pela Resolução (80\%). Verificou-se que houve correlação positiva entre coliformes com o fator pluviosidade e correlação negativa com a salinidade. Constatou-se também que a preamar de sizígia apresentou menor densidade de coliformes e diferiu significativamente dos outros estofos analisados. Concluiu-se que a concentração de coliformes nos locais analisados demonstrou variabilidade temporal e que sofre influência direta de salinidade, pluviosidade e amplitude de maré
\end{abstract}

Palavras-chave: coliformes totais; coliformes termotolerantes; qualidade da água; Crassostrea sp.

\begin{abstract}
The water in oysters harvesting areas of Cananeia Estuary was assessed by coliforms analysis throughout the 2005 to 2011 period. The thermotolerant coliforms presented geometric averages (18.80 NMP.100 $\mathrm{mL}^{-1}$ ) within the limits allowed by CONAMA 357/2005, but it did not reach the minimum percentile established by the Resolution (80\%). It was observed that there was a positive correlation between coliforms with rainfall factor and a negative one correlated with salinity factor. It was found also that the high tide showed lower density of coliforms and significantly differed from other upholstery analyzed. The analysis of the upholstery water showed variations in coliforms density and it is concluded that the concentration of coliforms in oyster production areas is directly influenced by salinity, rainfall and tidal range.
\end{abstract}

Keywords: total coliforms; thermotolerant coliforms; water quality; Crassostrea sp.

\section{INTRODUÇÃO}

O complexo estuarino-lagunar de Cananeia, Iguape e Paranaguá situa-se no extremo sul do estado de São Paulo (ao norte do Estado do Paraná, Brasil) e é uma das mais importantes áreas úmidas da costa brasileira em termos de biodiversidade e produtividade natural (UNESCO, 2005). Foi reconhecida nacional e internacionalmente como o terceiro ecossistema mais produtivo do Atlântico Sul pela União Internacional para a Conservação da Natureza (IUCN) em 1992 em razão de suas principais características ambientais estarem ainda muito bem preservadas (UNESCO, 2005).
O estuário é influenciado pelas forçantes ambientais (movimentos das marés, de descargas fluviais e dos ventos) e também pelas ações antrópicas (lançamento de efluentes domésticos e industriais não tratados) que afetam diretamente a qualidade da água e a distribuição dos organismos aquáticos (MIRANDA; CASTRO; KJERFVE, 2002). O complexo estuarino-lagunar de Cananeia é considerado o maior produtor de ostras em bancos naturais da Região Sudeste-Sul do Brasil e apresenta condições ambientais propícias, representando um dos principais recursos naturais explorados tanto para o comércio como para o consumo local (PEREIRA; HENRIQUES; MACHADO, 2003).

$\square$

'Programa de Pós-Graduação do Instituto de Pesca vinculado à Agência Paulista de Tecnologia dos Agronegócios (APTA) da Secretaria de Agricultura e Abastecimento (SAA) São Paulo (SP), Brasil.

IInstituto de Pesca vinculado à APTA da SAA - São Paulo (SP), Brasil.

${ }^{3}$ Centro de Pesquisa e Desenvolvimento de Peixes Ornamentais do Instituto de Pesca vinculado à APTA da SAA - São Paulo (SP)

Endereço para correspondência: Sonia Assami Doi - Instituto de Pesca - Avenida Francisco Matarazzo, 455 - Água Branca - 05001-900 - São Paulo (SP), Brasil -

E-mail: soniasdoi@gmail.com

Recebido: 07/05/13 - Aceito: 31/10/13 - Reg. ABES: 996 
Assim, torna-se de fundamental importância a verificação periódica da qualidade da água das áreas de cultivo para avaliar a qualidade microbiológica dos moluscos bivalves. Entretanto, a principal dificuldade do monitoramento da qualidade da água de um determinado local é o estabelecimento de indicadores adequados e a definição dos critérios a serem adotados para esta avaliação (BARBIERI \& DOI, 2012).

As águas do estuário de Cananeia podem ser enquadradas na Resolução CONAMA no 357 (BRASIL, 2005) como águas salobras por apresentarem salinidade entre 0,5 e 30 e na Classe 1, as quais são destinadas à proteção das comunidades aquáticas e à criação natural e/ou intensiva (aquicultura) de espécies destinadas à alimentação humana. Segundo a Resolução CONAMA n 357 ,

Para o cultivo de moluscos bivalves destinados a alimentação humana, a média geométrica da densidade de coliformes termotolerantes, de um mínimo de 15 amostras coletadas no mesmo local, não deverá exceder 43 NMP.100 mL ${ }^{-1}$, e o percentil 90\% não deverá ultrapassar 88 coliformes termolerantes por $100 \mathrm{~mL}$. (BRASIL, 2005, p. 295)

A sobrevivência de bactérias fecais no ambiente aquático é determinada por vários fatores ambientais, como variações de temperatura, salinidade, níveis de oxigênio, irradiação ultravioleta e pluviosidade (BORDALO; ONRASSAMI; DECHSAKULWATANA, 2002; HUGHES, 2003; CRAIG; FALLOWFIELD; CROMAR, 2004). Além dessas variáveis ambientais, a maré também tem grande influência da hidrodinâmica local (MILL; SCHLACHER; KAOULI, 2006), provocando a dispersão desses microrganismos e consequentemente variando a sua densidade no ambiente. Trabalhos como os de Kolm e Andretta (2003), Barbieri e Machado (2006) e de Barbieri et al. (2012) correlacionaram os fatores físicos, químicos e biológicos no ambiente aquático com os dados dos coliformes coletados, verificando que houve correlação entre esses dados e os fatores ambientais, como as médias pluviométricas e a variação da maré.

Os coliformes termotolerantes apresentam-se em grandes densidades nas fezes de animais de sangue quente e são utilizados como indicadores de poluição fecal recente das águas destinadas à potabilidade e balneabilidade (ALM; BURKE; SPAIN, 2003; POPE et al., 2003; CETESB, 2004; LEBARON et al., 2005). Esses organismos não encontram condições ideais para se multiplicar nas águas marinhas e morrem em um curto período de tempo. São facilmente isolados e identificados na água por meio de técnicas simples e rápidas (CETESB, 2004).

Diante da importância da qualidade da água onde ocorre a extração e o manejo das ostras Crassostrea sp., o presente trabalho teve como objetivo averiguar o nível de contaminação por coliformes nas áreas de produção desses organismos. A hipótese deste trabalho é de que com as variações ambientais físico-químicas $(\mathrm{pH}$, pluviosidade, temperatura, salinidade e variação da maré) haverá alteração das densidades dos coliformes. Os resultados obtidos foram comparados com a legislação vigente para verificação da qualidade da água em relação à contaminação microbiológica para a produção de moluscos bivalves.

\section{METODOLOGIA}

No período de janeiro de 2005 a dezembro de 2011, foram coletadas, quinzenalmente, amostras de águas estuarinas nos locais de produção e extração de ostra em Cananeia (Figura 1) em ambas as fases de maré, sizígia (quando temos máxima de maré alta e mínima de maré baixa) e quadratura ou maré de quarto (quanto à amplitude de maré não oscila muito). Os locais analisados foram Mandira, Itapitangui, Cooperostra, Taquari, Ilha da Casca e Retiro.

Cooperostra consiste em uma cooperativa comunitária dos produtores de ostras de Cananeia, situado próximo ao bairro Porto Cubatão, uma área urbana com falta de saneamento básico. Em Mandira, localiza-se a reserva extrativista de ostras do mangue e é a área mais extensa de cultivo de ostras. Ilha da Casca e Retiro ficam mais ao sul da ilha de Cananeia, afastados da área urbana. Ponto de Itapitangui localiza-se no rio Itapitangui, sendo área onde há maior risco de contaminação. A área de cultivo no rio Taquari está sujeita a efluentes domésticos não tratados vindos do bairro Porto Cubatão durante a baixa mar.

As variáveis ambientais (temperatura, $\mathrm{pH}$ e salinidade) foram obtidas no próprio local da coleta com o auxílio do equipamento de medição Multiparâmetro YSI-63. Os dados pluviométricos foram obtidos da estação meteorológica do Instituto Oceanográfico da USP em Cananeia, quinzenalmente do ano de 2011, sendo adotado como parâmetro o valor médio dos cinco dias que antecederam a coleta de água (Figura 1).

As amostras de água foram coletadas em profundidade de $15 \mathrm{a} 30 \mathrm{~cm}$, abaixo da superfície, com frasco voltado contra o sentido da correnteza (APHA, 2005). Utilizaram-se frascos de vidro neutro de borosilicato previamente autoclavados e, em seguida, as amostras foram armazenadas em caixa isotérmica refrigerada e transportadas ao laboratório. A metodologia utilizada para amostragem obedeceu às normas descritas pelo Standard methods for the examination of water and wastewater (APHA, 2005) e o método analítico utilizado para determinação do Número Mais Provável (NMP) de coliformes foi a Técnica de Tubos Múltiplos (APHA, 2005).

As amostras foram diluídas, conforme APHA (2005), em três séries com cinco tubos cada contendo Caldo Lauryl Sulfato de Sódio. Os tubos foram incubados em estufa a $35^{\circ} \mathrm{C}$ por $24-48$ horas. Os tubos que apresentaram produção de gás nos tubos de Durham e acidificados (coloração amarelada) foram considerados positivos.

Para confirmação de coliformes totais, os tubos que foram considerados positivos foram repicados em Caldo Verde Bile Brilhante (2\%) incubadas a $35 \pm 1^{\circ} \mathrm{C}$ por 48 horas. Para coliformes termotolerantes, as amostras foram repicadas e incubadas em EC (meio específico para Escherichia coli, utilizado como indicador de bactéria entérica patogênica) por um 


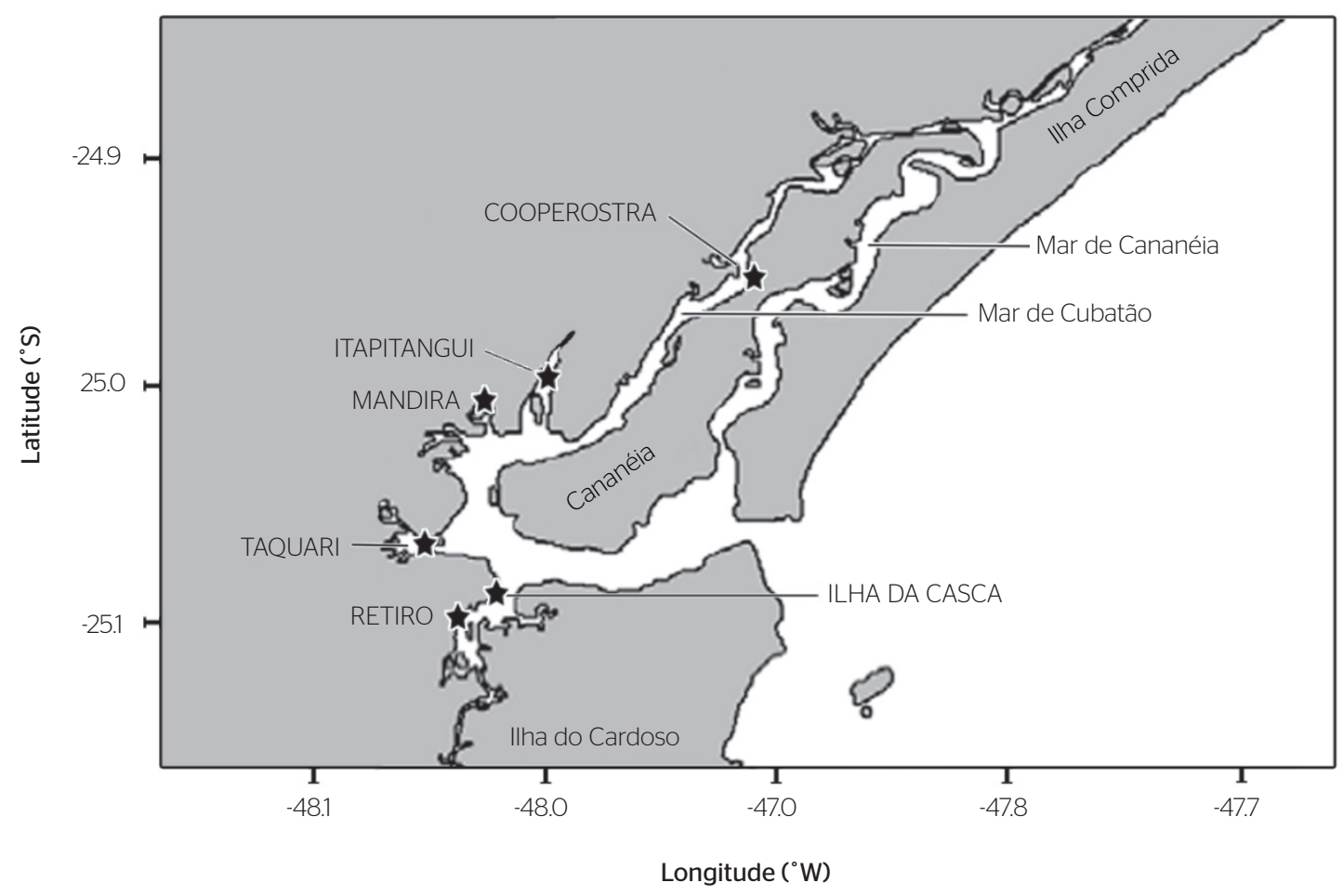

Figura 1 - Localizações dos pontos de coleta da água para análise colimétrica e mensuração dos dados ambientais in situ.

intervalo de 18 a 24 horas a $44,5 \pm 0,2^{\circ} \mathrm{C}$. Após esse período, foram considerados positivos os tubos que apresentaram produção de gás. O resultado das densidades de coliformes totais e termotolerantes foram expressos em Número Mais Provável por 100 mL (NMP.100mL $\left.\mathrm{m}^{-1}\right)$.

Utilizou-se o teste estatístico Shapiro-Wilk para verificar a normalidade (intervalo de confiança de 95\%). Como não apresentou distribuição normal, utilizou-se o teste não paramétrico de KruskalWallis (KW-H) para comparação do nível de contaminação dos coliformes nos diferentes pontos de coleta, tanto nos estofos de maré quanto na sazonalidade. Utilizou-se a Correlação Linear de Spearman para verificar se houve correlação entre a densidade de coliformes e os dados ambientais coletados neste trabalho. Utilizou-se teste estatístico de Friedman para comparar as densidades de coliformes totais e termotolerantes entre os estofos das marés (ZAR, 1999).

Coeficientes de correlação foram determinados entre o NMP de coliformes e a salinidade, temperatura e pluviosidade. Considerou-se Muito Fraca Correlação (MFC) para valores inferiores a 0,50; Fraca Correlação (FRC) com valores obtidos entre 0,50 e 0,70; Forte Correlação (FC) entre 0,70 e 0,89; e Correlação Muito Forte (CMF) para valores entre 0,90 e 1 (adaptado de CABRAL et al., 2006).

\section{RESULTADOS E DISCUSSÃO}

Os resultados do presente estudo demonstraram a variabilidade temporal da densidade de coliformes na área analisada. O NMP de coliformes totais (CT) das amostras variou de 2,0 a $1.600 \mathrm{NMP} .100 \mathrm{~mL}^{-1}$, com média geométrica de 38,46 NMP.100 $\mathrm{mL}^{-1}$. Coliformes termoto-

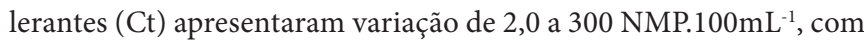
média geométrica de 18,80 NMP.100 $\mathrm{mL}^{-1}$. Verificou-se que os valores estão dentro dos limites permitidos pelo CONAMA 357/2005.

Entretanto, analisando o percentil das amostras pela legislação, verificou-se que somente $80 \%$ dos dados estavam abaixo do limite estabelecido, indicando que, apesar de a média geométrica estar dentro do estipulado, a quantidade de valores acima do valor determinado mostrou que a água estava insatisfatória no período estudado. Portanto, se faz necessário um acompanhamento contínuo dos contaminantes fecais das áreas com produção aquícola.

Monitorar a contaminação da água por meio da colimetria no estuário de Cananeia justifica-se pelo fato de essa região ser considerada um importante produtor de moluscos bivalves. Barbieri e Machado (2006) e Ristori et al. (2007) utilizaram a enumeração de coliformes a fim de averiguar o nível de contaminação fecal nas águas de extração de ostras em Cananeia, objetivando a possibilidade de riscos que esses microrganismos podem causar quando destinados ao consumo humano. No presente trabalho, altas densidades de coliformes podem ter sido influenciadas pelo lançamento de efluente de esgoto próximo aos pontos de coleta.

Verificou-se que os dados colimétricos aumentaram conforme aumentou o nível pluviométrico. No inverno, constatou-se a menor média de coliformes ( $\mathrm{CT}=24,29 \mathrm{NMP}$ e $\mathrm{Ct}=11,19 \mathrm{NMP})$ e a menor 
média pluviométrica $(0,54 \mathrm{~mm}$.dia). No verão, ao contrário, mensurou-se a maior média pluviométrica (2,54 mm.dia), com elevada densidade de coliformes (CT=110,23 NMP e Ct=41,69 NMP) (Tabela 1).

Ristori et al. (2007) realizaram estudos na costa sul do Brasil, em que obtiveram tendências de contaminação relacionadas às variações sazonais, detectando um nível elevado de coliformes fecais no verão, provavelmente em decorrência da pluviosidade e do aumento típico da população turística na época. Neste trabalho, altas densidades de coliformes no verão indicam um elevado nível de contaminação por efluentes lançados na água sem tratamento, ocasionado pelo afluxo de turistas e grandes volumes pluviométrico, que aumenta a vazão de esgotos gerados nessa época. Houve diferença significativa entre as sazonalidades nas densidades de coliformes totais ( $\mathrm{KW}-\mathrm{H}=13,71$ e $\mathrm{p}=0,0033$ ) e termotolerantes (KW-H=13,59 e $\mathrm{p}=0,0035)$.

Por meio da correlação de Spearman, observou-se que houve uma correlação muito forte positiva entre a pluviosidade e os coliformes totais $(r=0,95, p<0,0001)$ e termotolerantes $(r=0,94, p<0,0001)$ (Figura 2), concordando com estudos de Barbieri e Machado (2006), Vieira et al. (2008) e Miquelante e Kolm (2011). Esses trabalhos descreveram que a pluviosidade interfere nas densidades de coliformes na água, pois essa forçante tem a capacidade de arrastar esgotos e resíduos sólidos para os cursos d'água que, por sua vez, afluem para o estuário.

Neste estudo, mensuraram-se valores de salinidade entre 0,5 e 25,4 no período coletado e, apesar da acentuada variação, os resultados mostraram uma correlação negativa fraca entre esse parâmetro e a densidade de coliformes (CT: $r=-0,45$ e $\mathrm{p}=0,0075$, Ct: $\mathrm{r}=-0,39$ e $\mathrm{p}=0,024$ ). Resultados similares foram descritos por Ramos et al. (2010), os quais analisaram a qualidade da água salina de fazendas marinhas em Santa Catarina e verificaram que os coliformes apresentaram uma fraca correlação negativa com a salinidade.

Observou-se que no inverno a média da salinidade foi mais elevada $(20,62)$ comparada com as outras estações do ano, mas a temperatura e a pluviosidade apresentaram as menores médias, característica de regiões subtropicais. No verão, constatou-se o inverso, com maior média colimétrica e menor média de salinidade. Estatisticamente, não apresentou correlação significativa, concordando com trabalho de Silva et al. (2003). Bordalo, Onrassami e Dechsakulwatana (2002) relataram que os coliformes têm pouca tolerância às altas salinidades das águas marinhas, assim sua detecção nesse ambiente denota uma descarga recente e constante de matéria fecal. Esses autores descreveram que a salinidade tendeu a ser menor nas épocas de chuva e os valores das bactérias fecais, mais elevados.

De acordo com Kolm e Andretta (2003), a amplitude da variação da salinidade em estuários é muito alta, podendo ser encontradas nesse

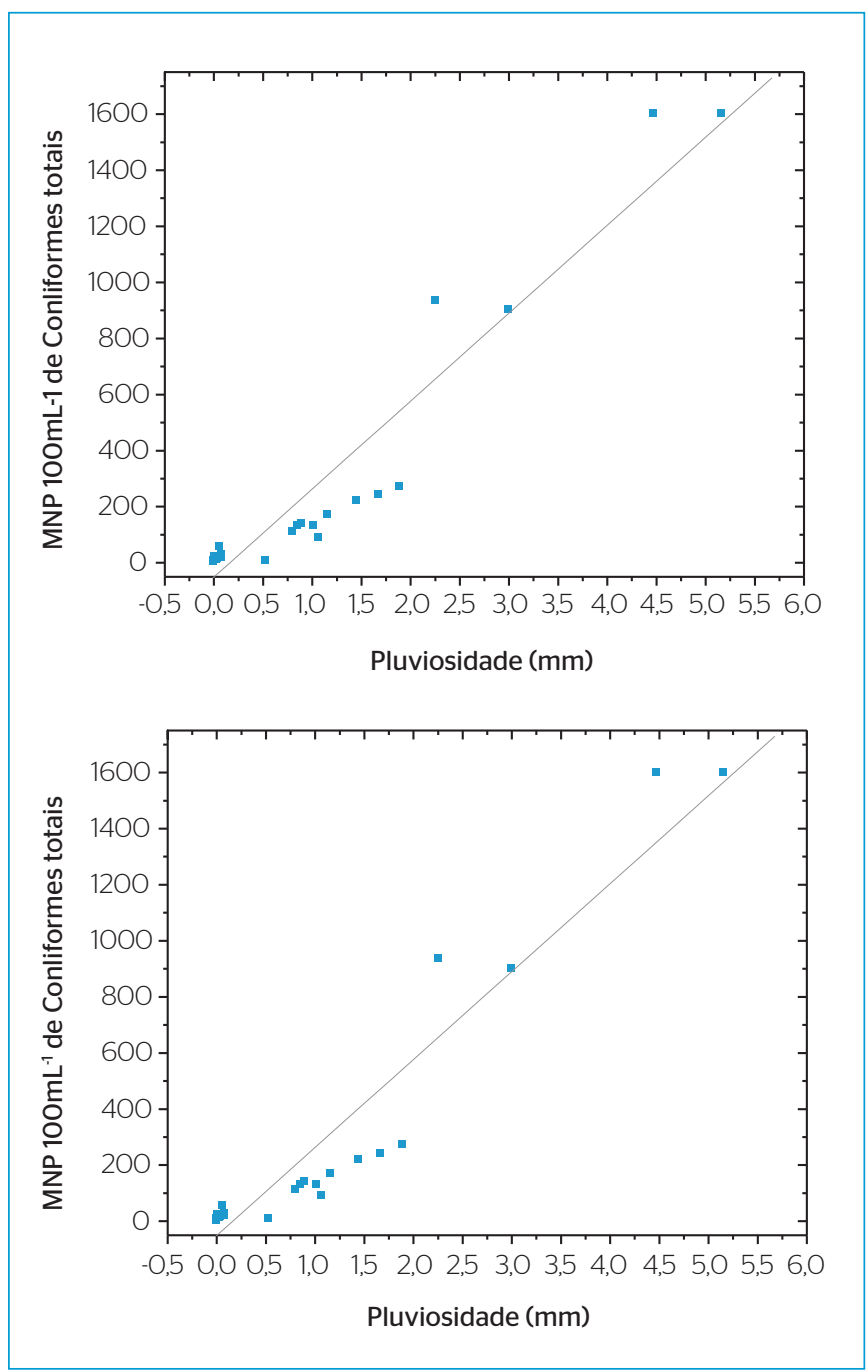

Figura 2 - Correlação entre as médias pluviométricas $(n=24)$ e os valores de coliformes totais $(R=0,95$ e $p<0,0001)$ e termotolerantes $(R=0,94$ e $p<0,0001)$. O resultado apresentou uma correlação positiva, indicando que a densidade de coliformes na água foi elevada com o alto índice de pluviosidade.

Tabela 1 - Média geométrica (desvio padrão geométrico) dos coliformes totais e termotolerantes em relação à sazonalidade em NMP.100mL¹. Média das variações ambientais: salinidade, temperatura $\left({ }^{\circ} \mathrm{C}\right)$, pluviosidade (mm.dia) e pH e seus respectivos desvios padrão entre parênteses.

\begin{tabular}{l|c|c|c|c|c|c} 
& Coliformes totais & Coliformes termotolerantes & Salinidade & Temperatura & Pluviosidade & pH \\
\hline Outono & $32,89(2,95)$ & $17,10(2,95)$ & $18,50(4,27)$ & $22,90(2,84)$ & $1,60(1,50)$ & $7,36(0,56)$ \\
\hline Inverno & $24,29(4,58)$ & $11,19(3,31)$ & $20,62(4,43)$ & $19,62(2,12)$ & $0,54(0,64)$ & $7,20(0,61)$ \\
\hline Primavera & $25,71(4,22)$ & $16,46(5,45)$ & $16,60(5,37)$ & $23,58(1,59)$ & $1,44(1,70)$ & $7,09(0,62)$ \\
\hline Verão & $110,23(4,68)$ & $41,69(4,00)$ & $12,30(6,59)$ & $26,33(1,64)$ & $2,54(2,00)$ & $6,98(0,58)$ \\
\hline
\end{tabular}


ecossistema tanto bactérias que apresentam adaptações para tolerar elevadas salinidades (halofílicas) como bactérias que vivem em águas com baixo teor de sal (halofóbicas).

A temperatura da água apresentou uma variação sazonal bem regular. No período amostral, a temperatura variou entre 17,4 e $28,4^{\circ} \mathrm{C}$, sendo a mínima registrada no mês de agosto (inverno) e a máxima no mês de fevereiro (verão). Verificou-se correlação muito fraca entre a temperatura da água e a colimetria (CT: $r=0,16, p=0,34$ e Ct: $\mathrm{r}=0,062, \mathrm{p}=0,73)$, concordando com trabalhos de Ristori et al. (2007) e Ramos et al. (2010).

O valor médio do $\mathrm{pH}$ foi de 7,16, sendo o mínimo de 5,89, observado no verão de 2007 , e o máximo de 8,26 , no inverno de 2008. O ambiente com pH ácido (em torno de 5,0) favorece a sobrevivência da $E$. coli ao passo que o $\mathrm{pH}$ da água do mar (em torno de $8,0)$ contribui para um efeito deletério na sobrevivência da bactéria (ROZEN \& BELKIN, 2001; MIGNANI et al., 2013). Galvão et al. (2006) analisaram a contaminação microbiológica nas águas de cultivo de mexilhões em Ubatuba (SP) com valores de $\mathrm{pH}$, porém constataram que não estavam relacionados entre si.

Durante o estofo de preamar e baixa-mar da quadratura, as densidades de coliformes totais foram bem maiores em relação à maré de sizígia. Entretanto, em relação aos coliformes termotolerantes (Figura 3), verificou-se que as densidades foram maiores no estofo de baixa-mar de sizígia seguido pelo estofo de baixa-mar de quadratura. Esse período de coleta foi caracterizado por maior pluviosidade, podendo ter influenciado nos valores coletados. Resultado similar foi observado no trabalho de Miquelante e Kolm (2011) na desembocadura da Gamboa Olho d'água (PR), onde valores elevados de coliformes termotolerantes foram observados nos períodos de chuva durante a baixa-mar.

Segundo Kolm e Andretta (2003), os maiores valores de coliformes totais registrados ocorreram durante a maré baixa no estudo realizado no córrego do Perequê, Pontal do Sul (PR), evidenciando uma relação direta entre as marés e a densidade de coliformes. Ainda segundo o autor, esse período foi caracterizado por altas pluviosidades, o que também pode ter influenciado a alta densidade registrada.

Por meio do teste estatístico de Friedman, compararam-se os valores de coliformes no estofo de preamar e baixa-mar da sizígia e quadratura e encontrou-se diferença significativa entre preamar sizígia e baixa-mar sizígia, preamar quadratura e baixa-mar quadratura (Tabela 2). Na comparação entre baixa-mar de sizígia e preamar de quadratura somente coliforme termotolerante apresentou diferença significativa $(\mathrm{p}=0,006)$.

A ocupação desordenada do solo, os loteamentos irregulares, o avanço imobiliário sobre as regiões de mangues e restingas e a falta de saneamento básico constituem fonte permanente de poluição

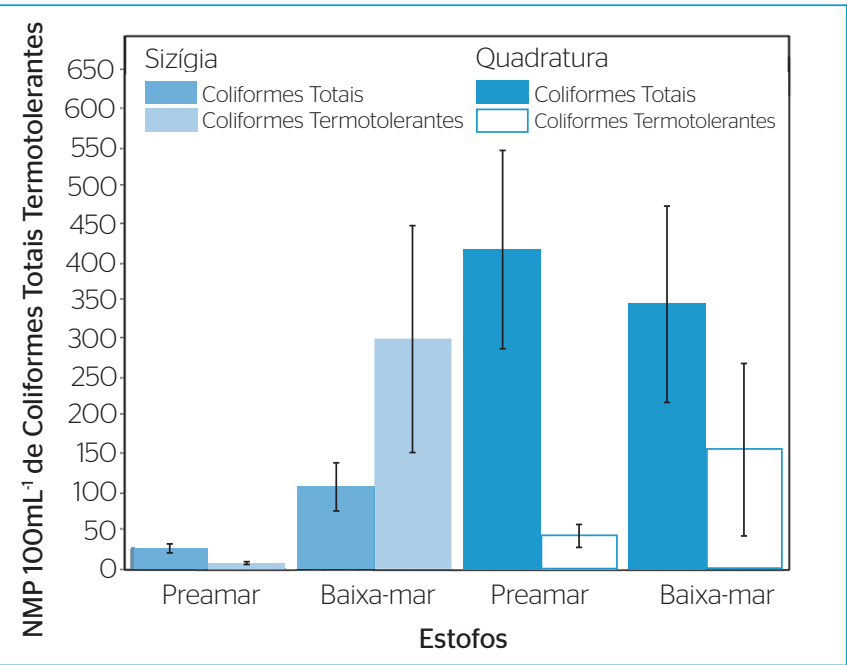

Figura 3 - Médias das densidades de coliformes totais e termotolerantes na água em relação ao estofo das marés de sizígia e quadratura. As barras representam os respectivos desvios padrão.

Tabela 2 - Teste não paramétrico de Friedman comparando as densidades de coliformes totais e termotolerantes entre os estofos de preamar e baixa-mar, e os estofos de sizígia e quadratura (graus de liberdade 3 , $<0,05)$. Em negrito, os valores que apresentaram diferença significativa.

\begin{tabular}{l|c|c} 
Estofos & $\begin{array}{c}\text { Coliforme } \\
\text { total }\end{array}$ & $\begin{array}{c}\text { Coliforme } \\
\text { termotolerante }\end{array}$ \\
\hline $\begin{array}{l}\text { Preamar sizígia x baixa-mar sizígia } \\
\begin{array}{l}\text { Preamar sizígia x preamar qua- } \\
\text { dratura }\end{array}\end{array}$ & 0,0266 & 0,0018 \\
\hline $\begin{array}{l}\text { Preamar sizígia x baixa-mar } \\
\text { quadratura }\end{array}$ & 0,0009 & 0,0212 \\
\hline $\begin{array}{l}\text { Baixa-mar sizígia x preamar } \\
\text { quadratura }\end{array}$ & 0,0004 & 0,0106 \\
\hline $\begin{array}{l}\text { Baixa-mar sizígia x baixa-mar } \\
\text { quadratura }\end{array}$ & 0,9875 & 0,0062 \\
\hline $\begin{array}{l}\text { Preamar quadratura x baixa-mar } \\
\text { quadratura }\end{array}$ & 0,6698 & 0,0514 \\
\hline
\end{tabular}

do estuário por resíduos orgânicos e esgotos domésticos, tornando alguns locais sujeitos à contaminação, principalmente em determinadas épocas do ano (BARBIERI \& MACHADO, 2006; BARBIERI \& DOI, 2012). É difícil explicar os valores altos de coliformes no estuário de Cananeia, pois se trata de uma cidade de pouco mais de 11.000 habitantes, onde $50 \%$ do esgoto é tratado (BARBIERI \& MACHADO, 2006).

O acompanhamento das densidades de coliformes em vários pontos do estuário se faz necessário, com o objetivo de averiguar as suas densidades durante as variações das marés e principalmente a eficiência da estação de tratamento de esgoto de Cananeia. Além disso, faz-se necessária a determinação microbiológica nas águas das várias localidades onde se estão cultivando ostras, para se evitar risco à saúde do consumidor. 


\section{CONCLUSÕES}

As médias geométricas dos microrganismos analisados das amostras de água coletadas estavam dentro do padrão estipulado pela legislação vigente, mas o cálculo do percentil das amostras apresentou-se inferior ao limite determinado pelo CONAMA.

As variações ambientais influenciaram nas flutuações das concentrações dos microrganismos, nas quais a pluviosidade teve correlação positiva com o índice bacteriano e a salinidade, correlação negativa. Quanto maior o índice de chuva, mais elevados os valores de coliformes encontrados. Enquanto na salinidade, quanto maior seu índice, menor as concentrações de coliformes.
A análise dos estofos de maré apresentou variações nas densidades colimétricas ao longo do estudo. Preamar de sizígia apresentou menor densidade de coliformes e diferiu significativamente dos outros estofos analisados em relação à densidade de coliformes, confirmando a hipótese de que a maré pode influenciar na analise microbiológica da água.

Concluiu-se que a concentração de coliformes nos locais de produção de ostras sofre influência direta de salinidade, pluviosidade e amplitude de maré.

Há a necessidade de determinar a densidade microbiológica em vários pontos do estuário onde se cultiva a ostra, para prevenir contaminações bacteriológicas do ambiente e evitar risco para a saúde dos consumidores.

\section{REFERÊNCIAS}

ALM, E.W.; BURKE, J.; SPAIN, A. (2003) Fecal indicator bacteria are abundant in wet sand at freshwater beaches. Water Research, v. 37, n. 16, p. 3978-3982.

American Public Health Association (APHA). (2005) Multiple tube fermentation technique for members of the coliform group. In: CLESCERL, L.S.; GREENBERG, A.E.; EATON, A.D. (editors). Standard Methods for the Examination of Water and Wastewater. 20th ed. Washington, DC: American Public Health Assn, $1082 \mathrm{p}$.

BARBIERI, E. \& DOI, S.A. (2012) Acute toxicity of ammonia on juvenile Cobia (Rachycentron canadum, Linnaeus, 1766) according to the salinity. Aquaculture International, v. 20, n. 2, p. 373-382.

BARBIERI, E.; BONDIOLI, A.C.; WOICIECHOVSKI, E.; ZAPOTOSKI, S.M.K. (2012) Microbiology quality of the oysters cultivation water marketed in Cananeia-SP, Brazil. O Mundo da Saúde, v. 36, n. 4, p. 541-547.

BARBIERI, E. \& MACHADO, I.C. (2006) Qualidade microbiológica da água de cultivo de Ostra (Crassostrea brasiliana) comercializada em Cananéia (SP), Brasil. Comunicação Científica. In: IV Congreso Iberoamericano Virtual de Acuicultura (CIVA), p. 113-120.

BORDALO, A.A.; ONRASSAMI, R.; DECHSAKULWATANA, C. (2002) Survival of fecal indicator bacteria in tropical estuarine waters (Bangpakong River, Thailand). Journal Applied Microbiology, v. 93, n. 5, p. 864-871.

BRASIL. Ministério do Meio Ambiente. Conselho Nacional do Meio Ambiente (CONAMA) (2005) Resolução n 357, do dia 17 de março de 2005. Dispõe sobre a classificação dos corpos de água e diretrizes ambientais para seu enquadramento, bem como estabelece as condições e padrões de lançamento de efluentes, e dá outras providencias. Diário Oficial da República Federativa do Brasil, Brasília, DF.

CABRAL, S.A.S.; AZEVEDO JUNIOR, S.M.; LARRAZABAL, M.E. (2006) Abundância sazonal de aves migratórias na área de proteção ambiental de Piaçabuçu, Alagoas, Brasil. Revista Brasileira Zoologia, v. 23, n. 3, p. 865-869.
CETESB - Companhia de Tecnologia de Saneamento Ambiental. (2004) Relatório de qualidade das águas litorâneas do estado de São Paulo: balneabilidade das praias 2003. São Paulo: CETESB, 226 p.

CRAIG, D.L.; FALLOWFIELD, H.J.; CROMAR, N.J. (2004) Use of microcosms to determine persistence of Escherichia coli in recreational coastal water and sediment and validation with in situ measurements. Jornal \& Applied Microbiology, v. 96, n. 5, p. 922-930.

GALVÃO, J.A.; FURLANI, E.F.; SÁLAN, E.O; PORTO, E.; OETTERER, M. (2006) Características físico-químicas e microbiológicas (Staphylococcus aureus e Bacillus cereus) da água e dos mexilhões cultivados em Ubatuba, SP. Ciências Agrotécnicas, v. 30, n. 6, p. 1124-1129.

HUGHES, K.A. (2003) Influence of seasonal environmental variables on the distribution of presumptive fecal coliforms around a research station in Antarctica. Applied Environmental Microbiology, v. 69, n. 8, p. 4884-4891.

KOLM, H.E. \& ANDRETTA, L. (2003) Bacterioplancton in different tides of the Perequê tidal creek, Pontal do Sul, Paraná, Brazil. Brasilian Journal of Microbiology, v. 34, n. 2, p. 97-103.

LEBARON, P.; HENRY, A.; LEPEUPLE, A.S.; PENA, G.; SERVAIS, P. (2005) An operational method for the real-time monitoring of $E$. coli numbers in bathing waters. Marine Pollution Bulletin, v. 50, n. 6, p. 652-659.

MIGNANI, L.; BARBIERI, E.; MARQUES, H.L.A.; OLIVEIRA, A.J.F.C (2103). Coliform densities in oyster culture waters and their relationship with some environmental factors. Pesquisa Agropecuária Brasileira, v. 48, n. 6 , p. 1-8.

MILL, A.; SCHLACHER, T.; KAOULI, M. (2006) Tidal and longitudinal variation of faecal indicator bacteria in an estuarine creek in south-east Queensland, Austrália. Marine Pollution Bulletin, v. 52, n. 8, p. 881-891.

MIQUELANTE, F.A. \& KOLM, H.E. (2011) Indicadores microbiológicos de poluição fecal na desembocadura da Gamboa Olho d'Água, Paraná: subsídio para o monitoramento da balneabilidade do Brasil. UEPG Biology Health Science, v. 17, n. 1, p. 21-35. 
MIRANDA, L.B.; CASTRO, B.M.; KJERFVE, B. (2002) Princípios de Oceanografia Física de Estuários. São Paulo: Editora da Universidade de São Paulo, 411 p.

PEREIRA, O.M.; HENRIQUES, M.B.; MACHADO, I.C. (2003) Estimativa da curva de crescimento da ostra Crassostrea brasiliana em bosques de mangue e proposta para a sua extração ordenada no estuário de Cananéia, SP, Brasil. Boletim do Instituto de Pesca, v. 29, n. 1, p. 19-28.

POPE, M.L; BUSSEN, M.; FEIGE, M.A.; SHADIX, L.; GONDER, S.; RODGERS, C.; CHAMBERS, Y.; PULZ, J.; MILLER, K.; CONNELL, K.; STANDRIDGE, J. (2003) Assessment of the effects of holding time and temperature on Escherichia coli densities in surface water samples. Applied Environmental Microbiology, v. 69, n. 10, p. 6201-6207.

RAMOS, R.J.; PEREIRA, M.A.; MIOTTO, L.A.; FARIA, L.F.B.; SILVERIRA JUNIOR, N.; VIEIRA, C.R.W. (2010) Microrganismos indicadores de qualidade higiênico-sanitária em ostras (Crassostrea gigas) e águas salinas de fazendas marinhas localizadas na Baía Sul da Ilha de Santa Catarina, Brasil. Revista do Instituto Adolfo Lutz (Impr.), v. 69, n. 1, p. 29-37.

RISTORI, C.A.; IARIA, S.T.; GELLI, D.S.; RIVERA, I.N.G. (2007) Pathogenic bacteria associated with oysters (Crassostrea brasiliana) and estuarine water along the south coast of Brazil. International Journal of Environmental Health Research, v. 17, n. 4, p. 259-269.
ROZEN, Y. \& BELKIN, S. (2001) Survival of enteric bacteria in seawater. FEMS Microbiology Reviews, v. 25, n. 5, p. 513-529

SILVA, A.I.M.; VIEIRA, R.H.S.F.; MENEZES, F.G.R.; FONTELES-FILHO, A.A.; TORRES, R.C.O.; SANT'ANNA, E. (2003) Bacteria of fecal origin in mangrove oysters (Crassostrea rhizophorae) in the Cocó river estuary, Ceará state, Brazil. Brazilian Journal of Microbiology, v. 34 n.1-2, p. 126-130.

UNESCO - UNITED NATIONS EDUCATIONAL, SCIENTIFIC AND CULTURAL ORGANIZATION. (2005) World Network of Biosphere Reserves - SC/EES, The MAB Program, $19 \mathrm{p}$.

VIEIRA, R.H.S.F; ATAYDE, M.A.; CARVALHO, E.M.R.C.; CARVALHO, F.C.T.C.; FONTELES FILHO, A.A. (2008) Contaminação fecal da ostra Crassostrea rhizophorae e da água de cultivo do estuário do Rio Pacoti (Eusébio, Estado do Ceará): Isolamento e identificação de Escherichia coli e sua susceptibilidade a diferentes antimicrobianos. Brazilian Journal of Veterinary Research and Animal Science, v. 45, n. 38, p. 180-189.

ZAR, J.H. (1999) Biostatistical analysis. 4 ed. New Jersey: Prentice-Hall, 663 p. 